\title{
Constraint Analysis of Liaoning Scientific Foreign Language Talents with View to Bourdieu's Theory
}

\author{
Huanhuan Ren ${ }^{1, a^{*}}$ and Chi Ma ${ }^{2, b}$ \\ ${ }^{1}$ Teaching and Research Institute of Foreign Languages, Bohai University, Jinzhou, China \\ ${ }^{2}$ Jinzhou Institute of Forestry Research, Jinzhou Forestry Bureau, Jinzhou, China \\ arenhuanhuan2014@163.com, ${ }^{\mathrm{b}}$ machi2014@tom.com
}

Keywords: Constraint analysis; Liaoning; Scientific Foreign Language Talents; Bourdieu's Theory

\begin{abstract}
One can see that much difficulty has been faced by Chinese scholars and instructors whilst developing scientific foreign language talents. Drawing on Bourdieu's theory we recommend adopting a new approach for a more nuanced understanding of how complex elements hold back the development of scientific foreign language talents in Liaoning province of China. In this paper, three elements behind the idea of Bourdieu's theory are explicated and they are proved to provide both conceptual and methodological implications for developing Liaoning scientific foreign language talents. With view to Bourdieu's theory, the reality of Liaoning scientific foreign language talents can be denoted in two dimensions: development disequilibrium and development inefficiency. It's argued that three constraint factors behind the problematic phenomenon are identified and analyzed, i.e. the absence of habitus of learning agents, the mismatch of capital for learning context, and the less connection to economic field.
\end{abstract}

\section{Introduction}

One can see that much difficulty has been faced by Chinese scholars and instructors whilst developing scientific foreign language talents, and more efforts and endeavors should be made by Chinese researchers and learners to review this learning situation. Drawing on Bourdieu's theory we recommend adopting a new approach for a more nuanced understanding of how complex elements hold back the development of scientific foreign language talents in Liaoning province of China. This paper presents both conceptual implications of Bourdieu's theory of practice in the process of examining the development of Liaoning scientific foreign language talents. This thesis also explicates some main constraints in developing Liaoning scientific foreign language talents, and it's hoped that this small study will be conducive to the future development of scientific foreign language talents in Chinese educational field.

\section{Ideas about Bourdieu's Theory}

Habitus as Beliefs of Agents. The notion of habitus is central to Bourdieu's thought. Habitat refers to the system of embodied dispositions, tendencies that organize the ways in which individuals perceive the social world around them and react to it [1]. So what does Bourdieu mean by a set of "dispositions"? He gives various definitions, including a "tendency", "propensity" or "inclination" [2]. In other words, habitus is a set of attitudes and values, and one major component of the dominant habitus is a positive attitude towards education. In Bourdieu's works, habitus is usually shared by people with similar background (in terms of social class, religion, nationality, ethnicity, education, profession, etc.), as the habitus is acquired through mimesis [1]. The same habitus will produce different practices in different social fields, and the habitus can be changed by changed circumstances [3]. It's claimed that the habitus is an important theoretical object insofar as it saves Bourdieu's theory from becoming a pure rationalist positional formalism with disembodied agents embedded in fields and engaging in strategies to accumulate different kinds of capital and allows Bourdieu to analyze the 
social agent as a physical, embodied actor, subject to developmental, cognitive and emotive constraints and affected by the very real physical and institutional configurations of the field [4].

Capital as Required Resources. Each field values particular sorts of resources that Bourdieu named capital [5]. Agents need to be endowed with a specific quantity and structure of resources they can put at stake in order to obtain the right to enter a social field [6]. Bourdieu distinguishes between four types of capital, namely economic, cultural, social and symbolic capital [7], which agents mobilize in order to enter and move on social fields. Two capitals (i.e. cultural capital and social capital) deserve special attention here. According to Bourdieu, cultural capital can exist in three forms: in the embodied state, i.e., in the form of long-lasting dispositions of the mind and body; in the objectified state, in the form of cultural goods, which are the trace or realization of theories or critiques of these theories, problematic, etc.; and in the institutionalized state, a form of objectification which must be set apart because, as will be seen in the case of educational qualifications, it confers entirely original properties on the cultural capital which it is presumed to guarantee[8], while social capital refers to "the aggregate of the actual or potential resources which are linked to possession of a durable network of more or less institutionalized relationships of mutual acquaintance and recognition - or in other words, to membership in a group - which provides each of its members with the backing of the collectivity-owned capital, a 'credential' which entitles them to credit, in the various senses of the word[8]". Although all types of capital appear to be distinct, in reality, they are very closely linked to each other and can be converted [6].

Field as Macro Structure of Rules. Bourdieu's theory of social fields is one of his key contributions to social sciences and humanities. Bourdieu uses the concept of field to analyze modern society as a space of conflict and competition. What is the field? In Bourdieu's work, a field is a setting in which agents and their social positions are located. The position of each particular agent in the field is a result of interaction between the specific rules of the field, agent's habitus and agent's capital (social, economic and cultural)[9]. In his later work, Bourdieu understands these social fields as universe or microcosm in which the agents and institutions are integrated and interact with each other in accordance with field-specific rules, which is why the field represents the more structural part of Bourdieu's theory[10]. There is no global rule that applies to all fields. Bourdieu argues that due to their unique rules, fields are autonomous. However, he also qualifies that the autonomy is only relative as fields are embedded in a social space [11]. Rules are not formalized but rather tacit in nature and need to be internalized by the agents in order to demonstrate appropriate practices and strategies [8]. In sum, it's argued that social fields are the macro concept that structure Bourdieu's thoughts and that represent the entry point for Bourdieu's further concepts [12].

\section{The Reality of Liaoning Scientific Foreign Language Talents with View of Bourdieu' Theory}

Disequilibrium in Development. Social inequalities in educational attainment exist in cultivating Liaoning scientific foreign language talents. Some groups have made progress in reducing gaps while others lag behind. Some agents are in dominant positions, while some agents in dominated positions. According to Bourdieu, it is the structure of objective relations between the agents that determines what agents can and what they cannot do, i.e. which practices are possible and which not[10]. In other words, the education systems of industrialized societies function is in such a way as to legitimate class inequalities. Moreover, Bourdieu claims that social inequalities are legitimated by the educational credentials held by those in dominant position means that the education system has a key role in maintaining the status quo[13]. In other words, educational credentials help to reproduce and legitimate social inequalities, as higher-class individuals are seen to deserve their place in the social structure [10]. In sum, educational development disparities persist across regions in cultivating Liaoning scientific foreign language talents.

Inefficiency in Development. Bourdieu's thought can have important implications for the cultivation of Liaoning scientific foreign language talents. Research suggests that since the education system presupposes the possession of cultural capital, which few students in fact possess, there is a 
great deal of inefficiency in pedagogic transmission [13]. Bourdieu claims that, this is because students simply do not understand what their teachers are trying to get across, and this is particularly apparent in the universities, where students, afraid of revealing the extent of their ignorance and minimize the risks by throwing a smoke-screen of vagueness over the possibility of truth or error [13]. In general, research has found that cultural capital has some impact on educational attainment, but does not explain all or even most of the social class effect. It may be that cultural capital is more important in some countries than in others, or operates differently in different countries at different times. All in all, cultural capital is closely linked with educational attainment and the lack of it may lead to inefficiency in development of Liaoning scientific foreign language talents.

\section{Constraint Analysis of Liaoning Scientific Foreign Language Talents with View to Bourdieu' Theory}

The Absence of Habitus of Learning Agents. Scientific foreign language talents are troubled with insufficient habitus to cope with learning difficulties in scientific foreign language learning. The explanation is denoted in two dimensions: individual and collective. On one hand, the thing those learners don't reflection on their learning lead to the absence of habitus in coping with various difficulties. Just as Bourdieu suggested the presence of habitus allow individuals to find new solutions to new situations without calculated deliberation, based on their gut feelings and intuitions [14].This is made evident by the fact that the possess of habitus in dealing with new situations is on the duty of learners themselves, so the lower learner autonomy in Liaoning scientific foreign language talents lead to less critical thinking about why to learn and how to learn. It's not good for the development of habitus in learning field. On the other hand, the misguiding pedagogical approaches in cultivating Liaoning scientific foreign language talents is to be blamed for the absence of habitus. Misalignment of career and educational goals occurs when the minimum education required for passing examination as opposed to the competences and skills in scientific foreign language. Teachers may focus on the transmission of knowledge and underestimate the role learner's play in learning process, not to speak of the construction of learning beliefs and values of learning agents in scientific foreign language learning. When a person's desired occupation exceeds their educational expectations, the educational institution are less likely to be conducive to the cultivation of habitus of learning agents. In sum, low learner autonomy of individual learning agents and the misalignment of pedagogical approaches lead to the absence of habitus in seeking a better position in learning field and may be detrimental to the development of habitus of Liaoning scientific foreign learning agents.

The Mismatch of Capital for Learning Context. There will be no success in any form of learning without access to various capitals. It may be argued that the mismatch of capitals in foreign language learning context constitutes one constraint factor in developing Liaoning scientific foreign language talents. Numerous explanations have been proposed and debated concerning why some students are deprived of appropriate resources. Firstly, Liaoning scientific foreign language talents are faced with insufficient scientific language input. For better position in the occupational domain after graduation, Liaoning scientific foreign language talents are expected to demonstrate a strong command of scientific foreign language (i.e. foreign language for special purpose). Background knowledge on technologies and science is given tolerating agents; however the short of corresponding foreign language input is the pitfall in most pedagogical designs. It takes time and energy for Liaoning scientific foreign language talents to get access to the required resources. Secondly, the creation of communicative language scenario has been ignored for long by language instructors in China. Learners study a foreign language in college but never use it again. The fact is that students remain orally incompetent despite being structurally knowledgeable in the foreign language learning setting. And school classroom are replete with transferring knowledge and strategies on getting high scores in examination. It's a common norm in most part of China, including Liaoning province. Lastly, the part of cultural knowledge is not reached by Liaoning scientific foreign language talents. As there is no second language in China, any language except mandarin is called foreign language learning. 
The foreign language learning features a lack of authentic cultural communication which is critical for any foreign language. All in all, the mismatch of capital for learning context leads to the inefficient development of Liaoning scientific foreign language talents.

The Less Connection to Economic Field. The people best able to be in a better position in fields are the ones who can connect with outside world and take economic elements into consideration. One of the common criticisms leveled at cultivation of Liaoning scientific foreign language talents is the rigid educational mechanism. No education is given in a vacuum, and education should take account of things outside learning field. The less connection to economic field may be reflected in two ways. On one hand, educational objective will go to nowhere if economic situations and trends in local and global scenarios are not considered by Liaoning scientific foreign language talents. Common asked questions are: why should scientific foreign language talents be developed and what kind of scientific foreign language talents are needed? The answers lie in the economy. People are more aware that it is due to economic development that the number of available jobs and the number of jobs being created that require significant knowledge of English is on the rise. And that's the part people in educational field are more likely to be ignored. On the other, capitals will not be easy to be identified and utilized if main elements in economic field are not stressed in foreign language learning. Scientific foreign language talents are targeted for mastering the competency in foreign language for special purpose. The truth is that only the special purpose of learning foreign language is identified in the labor market, can the cultivation of Liaoning scientific foreign language talents be specific and effective. To sum up, the connection to economic field is necessary in cultivating Liaoning scientific foreign language talents, as language has a specific value which is marked by the economic variables and economy in the widest meaning indirectly and directly influences various language processes.

\section{Summary}

From above, three elements behind the idea of Bourdieu's theory are explicated and they are proved to provide both conceptual and methodological implications for developing Liaoning scientific foreign language talents. With view of Bourdieu' theory, the reality of Liaoning scientific foreign language talents can be denoted in two dimensions: development disequilibrium and development inefficiency. Moreover, three constraint factors behind the problematic phenomenon, i.e. the absence of habitus of learning agents, the mismatch of capital for learning context, and the less connection to economic field, are identified and analyzed. What's more, further research is called on to increase the development of Liaoning scientific foreign language talents in Chinese educational field.

\section{Acknowledgements}

This work is part of the project of On Cultivating and Developing Liaoning Scientific Foreign Language Talents with View to Bourdieu' Theory. This research was supported by the fund of Liaoning Planning of Philosophy and Social Science (Project No. L16CYY001).

\section{References}

[1] P. Bourdieu, Outline of a Theory of Practice, Cambridge University Press, 1977.

[2] P. Bourdieu, Cultural Reproduction and Social Reproduction. In Karabel, 1. And Halsey, A. H., eds, Power and Ideology in Education. OUP, Oxford, 1997.

[3] P. Bourdieu, the Logic of Practice, Polity Press, 1990.

[4] Lizardo, the Cognitive Origins of Bourdieu's Habitus, Journal for the Theory of Social Behaviour, 34 (2004).

[5] P. Bourdieu, L. J. D. Wacquant, an Invitation to Reflexive Sociology, the University of Chicago Press, 1992. 
[6] Accardo, Introduction à une sociologie critique,Lire Pierre Bourdieu, Éditions Agone, coll, Eléments , (382) 2006.

[7] P. Bourdieu, The forms of capital. In J. Richardson (Ed.) Handbook of Theory and Research for the Sociology of Education (New York, Greenwood), 1986.

[8] M. Walther, Reparation to France and Germany A Comparative Study Based on Bourdieu's Theory of Practice, Springer Gabler, Wiesbaden, 2014.

[9] P. Bourdieu, Distinction: a social critique of the judgement of taste, London: Routledge, 1984.

[10] P. Bourdieu, the Love of Art, Polity, 1997.

[11]P. Bourdieu, L'école conservatrice. Les inégalités devant l'école et devant la culture. Revue française de sociologie, 7 (1966).

[12] D. Golsorkhi, I. Huault, Pierre Bourdieu: critique et réflexivité comme attitude analytique, Revue française de gestion, 165 (2006).

[13] Sullivan, Bourdieu and Education: How useful is Bourdieu's theory for researchers? The Netherlands' Journal of Social Sciences, 38 (2002).

[14]P. Bourdieu, J. C. Passeron, Reproduction in Education, Society and Culture, Sage, London, second edition, 1990.

[15]P. Bourdieu, Distinction: A Social Critique of the Judgement of Taste, Harvard University Press, 1987. 